\title{
Effect of a Nonuniform Radial/Axial Tip Clearance on the Flow Field in a Mixed-Flow Pump
}

\author{
W. Li, ${ }^{1}$ L. L. Ji, W. D. Shi, Y. F. Ping, L. Zhou, and X. P. Jiang \\ National Research Center of Pumps and Pump System, Jiangsu University, Zhenjiang, China \\ ${ }^{1}$ lwjiangda@ujs.edu.cn
}

The effect of a nonuniform radial/axial tip clearance on the flow field in a mixed-flow pump was studied by numerical simulation of the unsteady flow in the pump with two tip clearance shapes using the standard Reynolds average Navier-Stokes turbulence model, and the equations were solved with the SIMPLEC computational algorithm. The external characteristics, distribution of static pressure, streamline flow of the tip clearance, and vorticity in the impeller are analyzed. The accuracy of numerical simulation was assessed by comparing experimental data with computational results. Although a nonuniform tip clearance leads to a decline in the pump head, which is more pronounced under part-load conditions, the configuration with a nonuniform tip clearance $(c=0.5-1 \mathrm{~mm})$ provides the more uniform velocity and pressure distribution both in the circumferential and axial directions, as the leakage vortex intensity is weakened and its shedding is suppressed. The research results pointed the way for improving the unsteady flow in the mixed-flow pump.

Keywords: mixed-flow pump, numerical simulation, tip clearance, tip leakage vortex.

Introduction. Mixed-flow pumps are widely used in agricultural irrigation and urban water supply, as well as the sea water desalination system and thermal power and nuclear power plants [1-3]. However, the internal flow field in the mixed-flow pump is hard to assess, especially, near the tip clearance of blade between the blade tip and shell wall. Due to the pressure difference between the blade pressure and suction surfaces, the leakage flow moves through the gap between the tip and pump shell wall. At the exit of the tip clearance, the leakage flow often collides with the mainstream and entrains into the tip leakage vortex. The pressure difference and tip clearance are intrinsic characteristics of rotating machinery, so the leakage flow is inevitable and must be considered.

The influence of the tip clearance flow on the performance and flow structure in fluid machinery has been studied by many researchers [4-6]. In previous studies, it was found that the swirling flows and vortex motions within unshrouded impellers are sensitive to the tip clearance flow. In the study of mixed-flow pump, structure design and optimization [7-9], flow field measurement and analysis [9, 10], hydraulic and cavitation performances prediction [11-14] were investigated. Kim et al. [15] performed numerical simulation to investigate the tip clearance effect on the pump head and hydraulic efficiency. The results showed that the tip clearance effect changes the shape of $Q-H$ curve. Van Esch and Cheng [16] conducted numerical and experimental studies on the relation between the instability in the head curve and the magnitude of unsteady hydraulic forces. It is found that the flow structure is greatly affected by the distance of the blade tip to the casing wall, while the spectral content of the forces shows evidence of rotating instabilities. It indicates that not only instability of the head curve' and unsteady forces are interrelated, but also rotating instabilities play a role in this phenomenon. Goto [17] investigated the flow phenomena around the positive slope region of the head-flow characteristic on a mixed-flow pump impeller at various tip clearances for both shrouded and unshrouded cases, and explained the interaction between the tip leakage flows and secondary flows and the formation of the wake regions in shrouded and unshrouded cases based on experimental observation and 
computations by the Dawes three-dimensional Navier-Stokes code. Bing et al. [18] carried out the hydraulic performance test of the mixed-flow pump under different blade tip clearances and various blade angles. The ratio of the mixed-flow pump efficiency reduction and the blade tip clearance variation $(\eta / \delta)$ varies with the flow rate coefficient revealing a parabolic trend. Few studies have considered a nonuniform tip clearance.

The main objective of this work is to numerically investigate the effects of the nonuniform tip clearance on the performance and flow field in a mixed-flow pump. Based on the numerical method, the internal flow characteristics with two tip clearances are simulated, particularly focusing on the leakage vortex generation and development. External characteristic, static pressure distribution, the streamline distribution of tip clearance and the vorticity distributions in the impeller are analyzed. The results can serve as references to improve the unsteady flow condition in the mixed-flow pump.

1. Research Model. The main parameters of the mixed-flow pump are as follows: flow rate $Q_{d e s}=380 \mathrm{~m}^{3} / \mathrm{h}$, head $H=6 \mathrm{~m}$, rotate speed $n=1450 \mathrm{rpm}$, specific speed $n_{s}=480$, number of blades $Z=4$, and number of guide vane blades $Z_{d}=7$. Threedimensional model of inlet segment, impeller, guide blade, circular volute chamber and outlet segment is established, using the Pro/Engineer software. The 3D models of impeller and guide vane are shown in Fig. 1.

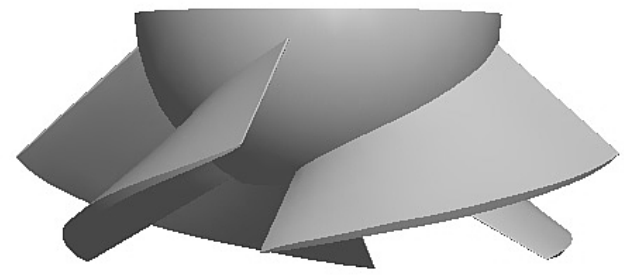

a



$\mathrm{b}$

Fig. 1. Three-dimensional model: (a) impeller; (b) guide vane.

\section{Numerical Procedure.}

2.1. Turbulence Model. Numerical simulation is widely used to predict the performance of hydraulic machineries, which provides a new way for researchers to understand the flow condition inside the complicated hydraulic components while saves the cost for the experiment. At present, three categories of turbulent models with different calculation effort requirements are available, namely, direct numerical simulation (DNS), large eddy simulation (LES) and Reynolds average Navier-Stokes simulation (RANS). As the limitation of the computer source, RANS models are most widely used recently. As a RANS model, kinetic energy $k$ vs. dissipation rate $\varepsilon$ model is widely used for numerical simulationof centrifugal pumps and proved to be quite accurate. In this study, this $k-\varepsilon$ model was selected to predict the performance of the mixed-flow pump, using the following equations:

$$
\begin{gathered}
\frac{\partial}{\partial t}(\rho k)+\frac{\partial}{\partial x_{j}}\left(\rho k u_{i}\right)=\frac{\partial}{\partial x_{j}}\left[\left(\mu+\frac{\mu_{t}}{\sigma_{k}}\right) \frac{\partial k}{\partial x_{j}}\right]+G_{k}+G_{b}-\rho \varepsilon-Y_{M}+S_{k}, \\
\frac{\partial}{\partial t}(\rho \varepsilon)+\frac{\partial}{\partial x_{j}}\left(p \varepsilon u_{i}\right)=\frac{\partial}{\partial x_{j}}\left[\left(\mu+\frac{\mu_{t}}{\sigma_{\varepsilon}}\right) \frac{\partial \varepsilon}{\partial x_{j}}\right]+C_{1 \varepsilon} \frac{\varepsilon}{k}\left(G_{k}+C_{3 \varepsilon} G_{b}\right)-C_{2 \varepsilon} \rho \frac{\varepsilon^{2}}{k}+S_{\varepsilon} .
\end{gathered}
$$


The expression of turbulent viscosity coefficient is

$$
\mu_{t}=\rho C_{\mu} \frac{k^{2}}{\varepsilon}
$$

Here $i$ and $j$ are the tensor symbols, $u_{i}$ is the velocity component $(\mathrm{m} / \mathrm{s}), x_{j}$ is the displacement component (m), $t$ is the time (s), $\mu_{t}$ is the turbulent viscosity $(\mathrm{Pa} / \mathrm{s}), \rho$ is the fluid density $\left(\mathrm{kg} / \mathrm{m}^{3}\right), k$ is the turbulent kinetic energy $\left(\mathrm{m}^{2} / \mathrm{s}^{2}\right), \varepsilon$ is the dissipation rate $\left(\mathrm{m}^{2} / \mathrm{s}^{3}\right), G_{k}$ is the turbulent kinetic energy produced by the average velocity gradient, $G_{b}$ is the production of turbulent kinetic energy caused by buoyancy, $Y_{M}$ is the effect of compressible velocity turbulence expansion on the total dissipation rate, $C_{\mu}$, $C_{1 \varepsilon}, C_{2 \varepsilon}$, and $C_{3 \varepsilon}$ are the empirical constants $\left(C_{\mu}=0.09, C_{1 \varepsilon}=1.44\right.$, and $\left.C_{2 \varepsilon}=1.92\right)$, $\sigma_{k}$ and $\sigma_{\varepsilon}$ are the Prandtl numbers corresponding to turbulent kinetic energy $k$ and dissipation rate $\varepsilon\left(\sigma_{k}=1.0\right.$ and $\left.\sigma_{\varepsilon}=1.3\right)$, and $S_{k}$ and $S_{\varepsilon}$ user defined.

2.2. Mesh and Boundary Conditions. Based on CFD commercial software, three-dimensional incompressible Navier-Stokes equation is used to describe internal flow of the pump, and the closed equation set of the standard $k-\varepsilon$ turbulence model is adopted to solve the incompressible Navier-Stokes equation with the SIMPLEC computational method. Second-order upwind scheme was used for the space discretization. Inlet velocity and outlet pressure are given as boundary conditions. The reference pressure is set a 1 atmospheric pressure, and the convergence accuracy is $10^{-4}$. The calculation domain is composed of segments from the pump inlet to the outlet of the circular volute chamber, which is meshed by hexahedral grid using ICEM software. Considering the tip clearance is very small compared with the diameter of the impeller, to ensure enough grid number in the tip clearance, the mesh inside the tip clearance is refined and the transition from tip clearance grid to the internal grid of impeller is kept uniform. In the impeller and the guide vane, the $\mathrm{J} / \mathrm{O}$ topological structure and the $\mathrm{H} / \mathrm{O}$ topological structure are adopted respectively. Y-block topological structure is used in the inlet section and the flow passage is formed by the periodic array. The $y^{+}$of the whole calculation domain is less than 100 , that is, the grid nodes in the first layer are located in the layer of logarithmic law, and the boundary layer is processed by the standard wall function. The computational grid of the entire domain is shown in Fig. 2, and refined mesh in the tip region is shown in Fig. 3.

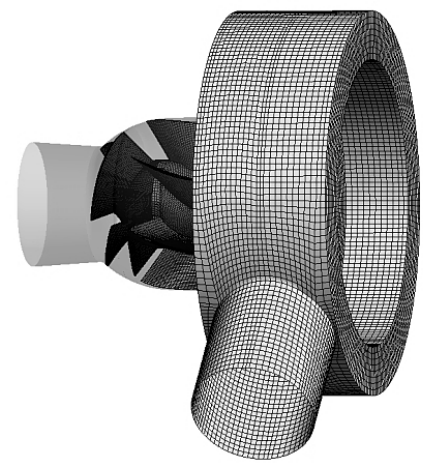

Fig. 2. Computational grid for the entire domain.

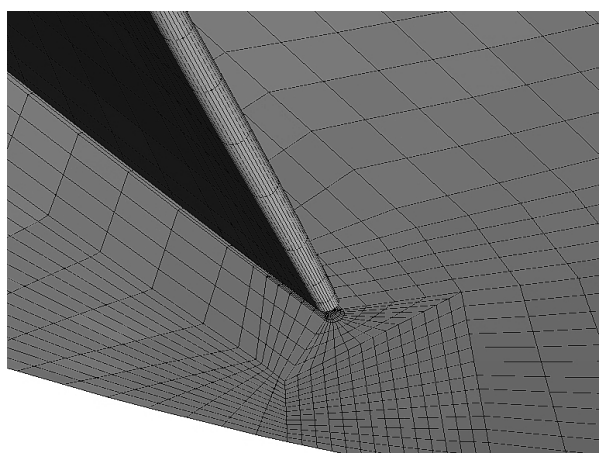

Fig. 3. Mesh of tip clearance.

2.3. Grid Independence Verification. To ensure the accuracy of the numerical result while reducing the computational effort, the grid independence study was carried out to select a reasonable mesh size. While doing the grid independence analysis, a set of meshes were generated using the same mesh topology, and the number of mesh nodes on the 
topological lines as well as the corresponding nodes were adjusted to create meshes with consistent quality but different cell numbers. Figure 4 shows the heads calculated with 10 different meshes using the same governing equations and boundary conditions. When the computing grid number is over 1.45 million, the change of head is very small, so the total grid number of the total calculation domain is about 1.45 million.

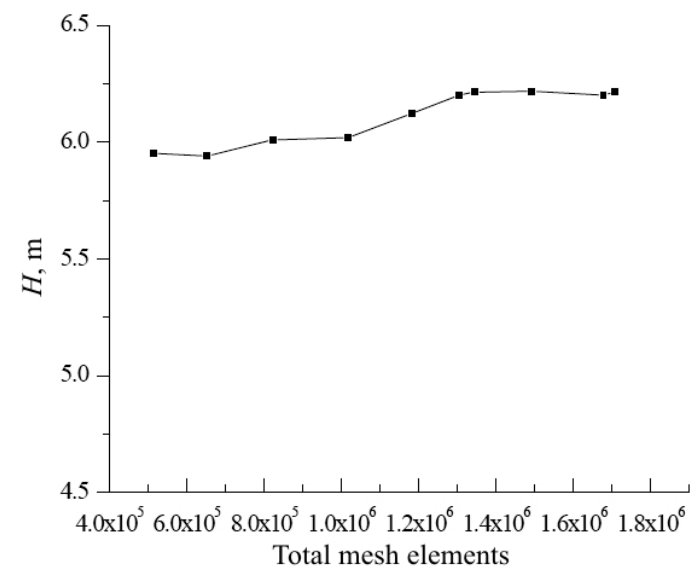

Fig. 4. Pump head calculated with different grid numbers.

3. Numerical Test Cases. The effect of the nonuniform tip clearance on the performance and flow field was investigated by conducting simulations of impellers with two tip clearance shapes. The tip clearance heights at the leading and trailing edges were selected, and the distribution of the tip clearance varied linearly along the tip. The original tip clearance $c$ is $0.8 \mathrm{~mm}$, while the minimum clearance of the nonuniform tip clearance $c$ is $0.5 \mathrm{~mm}$ at the blade leading edge and the maximum clearance $c$ is $1 \mathrm{~mm}$ in the blade trailing edge. The numerical test cases are shown in Fig. 5. The computational conditions, grid size, and boundary conditions were identical for two test cases except for the tip clearance profile.

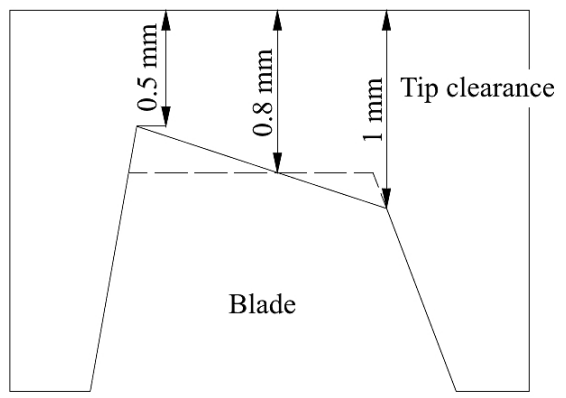

Fig. 5. Blade profile with different tip clearance values.

\section{Results and Discussion.}

4.1. Experiment Validation and Performance Prediction. External characteristic curves obtained by mixed-flow pumps test and numerical simulation are drawn respectively in the original case $(c=0.8-0.8 \mathrm{~mm})$, as shown in Fig. 6 .

It can be seen from this figure that the calculated head and efficiency are slightly higher than the experimental data at part-load operating condition. Under $1.2 Q_{\text {des }}$ flow condition, the simulated head and efficiency agree well with that tested from the experiment, and the error of the efficiency is lower than $5 \%$. Generally, the head and efficiency of 
numerical simulation are generally consistent with the performance of test measurement, which indicates that the mesh quality and turbulence model adopted in this calculation can accurately predict the external characteristic of the mixed-flow pump.

External characteristic curves of the nonuniform tip clearance are obtained, and compared with that of the original configuration, which is shown in Fig. 7.

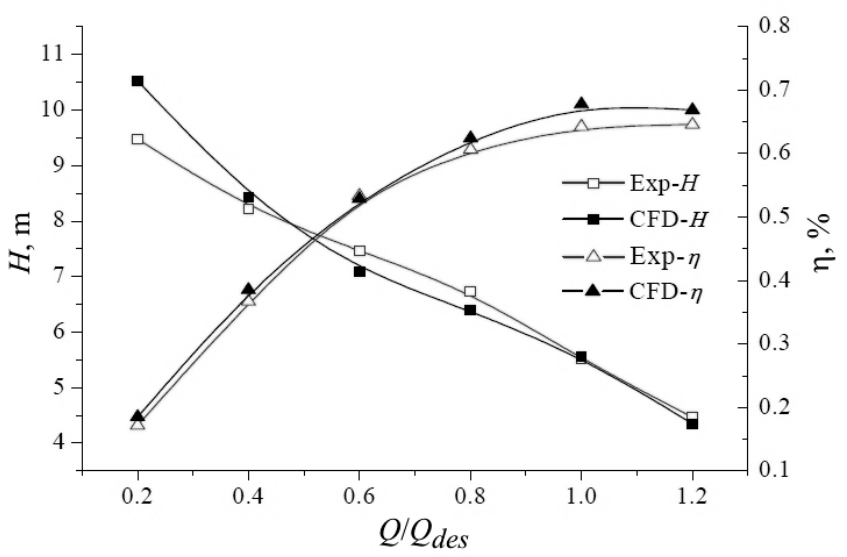

Fig. 6. Comparison between experimental and numerical simulation performance in the original case.

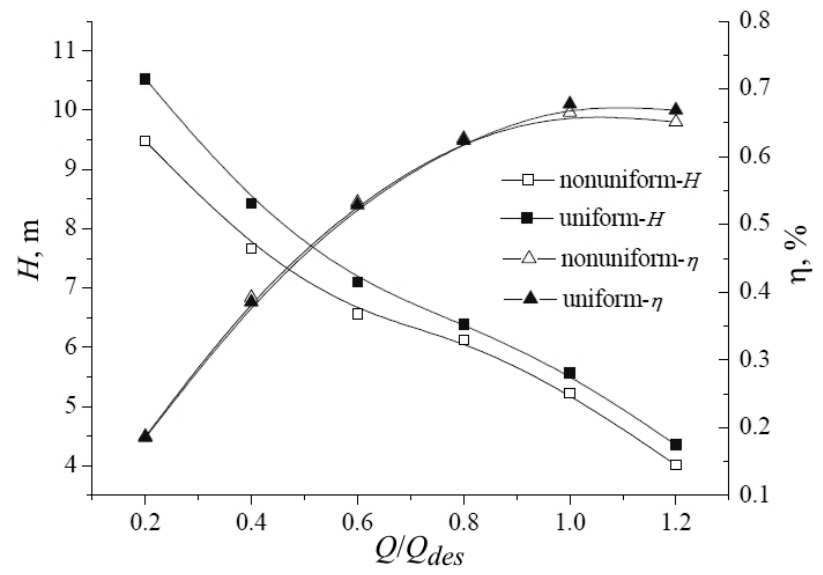

Fig. 7. External characteristic of mixed-flow pump with different blade height.

It can be seen from the figure that the head and efficiency of the pump with nonuniform tip clearance $(c=0.5-1 \mathrm{~mm})$ are slightly lower than that of the original geometry structure $(c=0.8-0.8 \mathrm{~mm})$. Under part-load operating condition, the head drop is more obvious, and the head gap gradually decreases with the increase of flow rate. The efficiency of mixed-flow pump in the two cases are close, with a little difference under overload operating condition $\left(Q=1.2 Q_{\text {des }}\right)$. The efficiency value of the nonuniform tip clearance blade is $3 \%$ lower than the original impeller. Thus, the nonuniform tip clearance plays an important role on the flow instability of mixed-flow pump, which is the main reason for the decline on the pump head and efficiency.

4.2. Distribution of Pressure and Velocity at 99\% Span Location. In this study, as shown in Fig. 8, the $S 1$ surface is a rotational surface at $99 \%$ span location for the impeller passages. Meanwhile, the $S 2$ surface is a meridian surface. In order to understand effects of tip clearance, the pressure distribution and velocity distribution on the $S 1$ surface is shown in Fig. 9. As seen in Fig. 9a, the pressure distribution at nonuniform tip clearance is more 


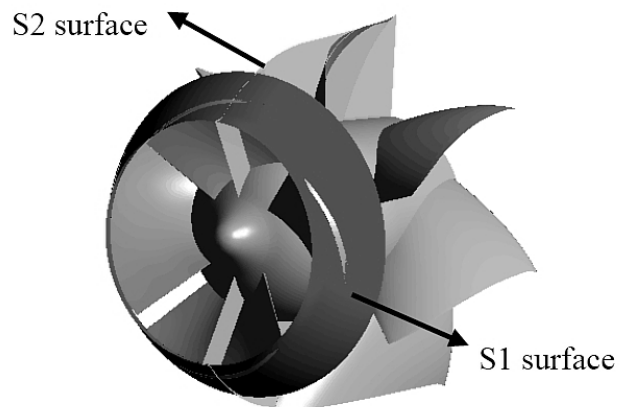

Fig. 8. Diagram of rotational surface at $99 \%$ span location and meridian surface.

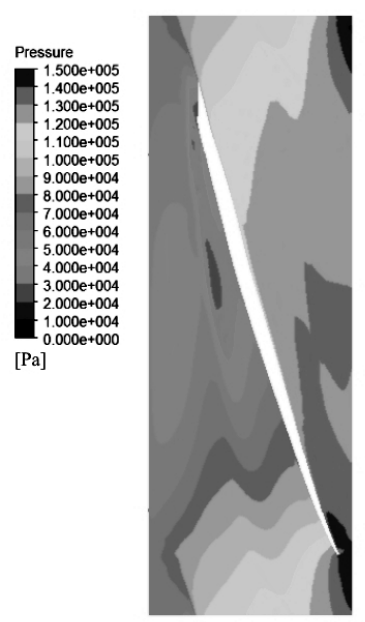

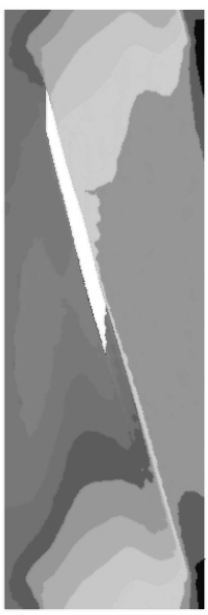
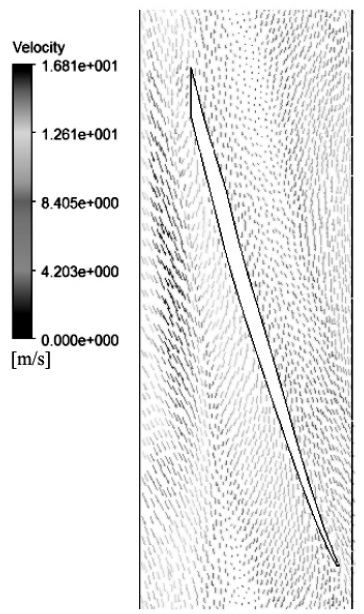

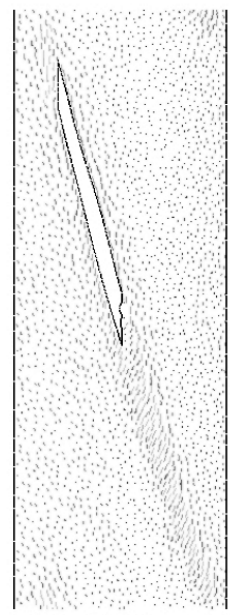

$\mathrm{b}$

Fig. 9. Pressure (a) and velocity (b) distributions on the $S 1$ surface (the left is the uniform tip clearance $c=0.8-0.8 \mathrm{~mm}$ and the right is the nonuniform tip clearance $c=0.5-1 \mathrm{~mm}$ ).

uniform than in the original pump, and the pressure gradient is smaller in the nonuniform tip clearance. Under the uniform clearance, there is an obvious low pressure area at the suction surface of the blade from leading edge to trailing edge, which is the tip leakage vortex formed at the tip of the blade. At blade outlet, high pressure area in the uniform tip clearance impeller is significantly greater than that in the impeller with nonuniform tip clearance. As the nonuniform tip clearance effect reduces the pressure difference between the impeller imports and exports, leading to a decrease in impeller head, which is consistent with the simulation result of the external characteristic. As can be seen from Fig. 9b, the velocity distribution of tip area with nonuniform tip clearance is very uniform, but under the uniform tip clearance, the low pressure zone on the side of the suction surface of the blade appears obvious high speed flow, which makes the flow of the gap region become unstable.

4.3. Tip Leakage Flow. The leakage flow interferes with the mainstream and changes the flow direction at the rim of the blade suction surface, which is entrained into the tip leakage vortex and causes the energy loss. The vorticity distribution of impeller flow passages in mixed-flow pump is shown in Fig. 10.

It can be seen from the diagram, vorticity in the tip clearance exists in both two kinds of impellers, but the vortex core is small under the nonuniform tip clearance $c=0.5-1 \mathrm{~mm}$. 

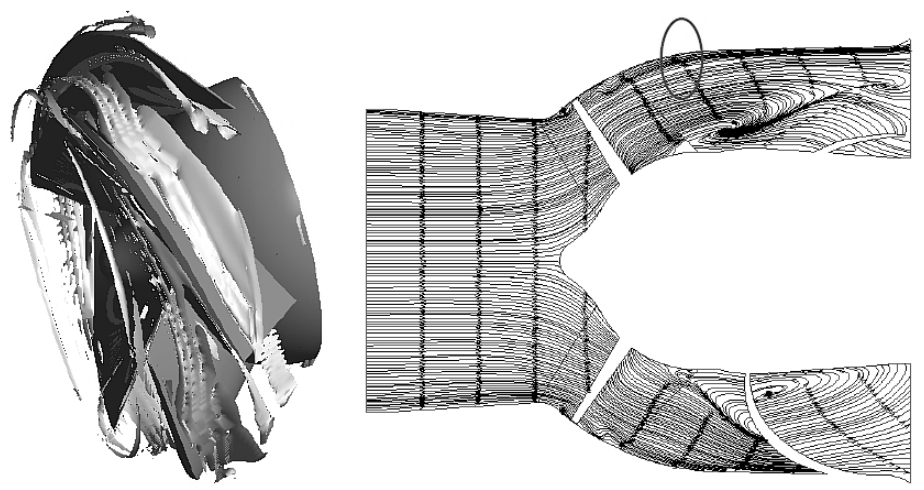

a
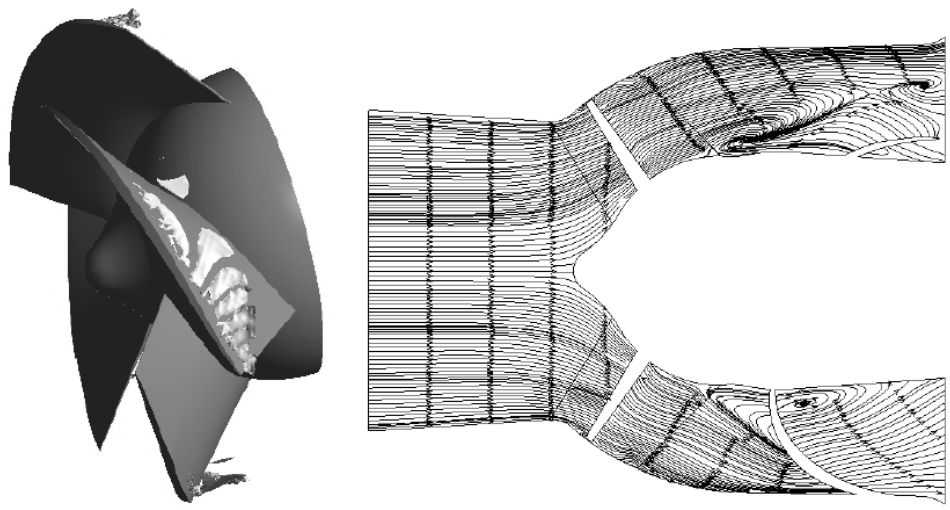

b

Fig. 10. Tip leakage vortex and streamlines in the meridian surface: (a) the uniform tip clearance $c=0.8-0.8 \mathrm{~mm}$; (b) the nonuniform tip clearance $c=0.5-1 \mathrm{~mm}$.

At the same time, under the uniform tip clearance $c=0.8-0.8 \mathrm{~mm}$, the tip leakage vortex intensifies obviously and occupies the whole flow passage, while leakage flow in the blade suction surface of the rim area formed a pronounced tip leakage vortex. By comparing the internal flow of mixed-flow pump with two clearances, it can be found that the vorticity is smaller at the $c=0.5-1 \mathrm{~mm}$ clearance and the flow field state in the whole flow passage is better. The streamlines in the meridian surface also indicated that a nonuniform tip clearance was more effective than a uniform tip clearance.

4.4. Streamline Distribution in the Tip Clearance Flow Field. Three cross sections through the impeller axis were intercepted at the same blade inlet, middle and outlet, as shown in Fig. 11. The pressure and streamline distribution of the three cross sections of the impeller are obtained in two cases, as shown in Fig. 12. In Section 1, the tip leakage vortex is observed in the pressure side of the blade with both two tip clearance shapes, which was caused by the tip leakage flow of former adjacent blade. However, the intensity of the leakage vortex in Section 1 is much higher in the nonuniform tip clearance impeller than that in the uniform tip clearance case, and the streamline along which the leakage vortex converges to the main stream is smoother in the nonuniform tip clearance case. In Section 2 , there is a clear tip leakage vortex in the suction side of the blade in the impeller with uniform tip clearance, while the vortex structure is not obvious in the case with nonuniform tip clearance. In Section 3, the leakage vortex from the uniform tip clearance further increase and moves downstream, which seriously interfere with the mainstream, causing 


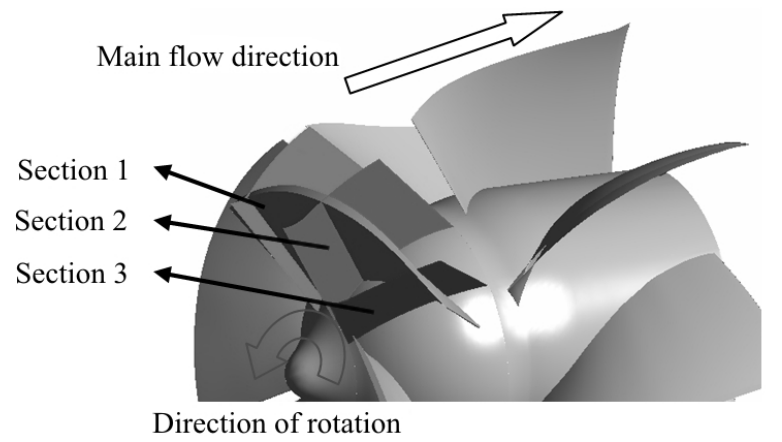

Fig. 11. Position of cross sections.

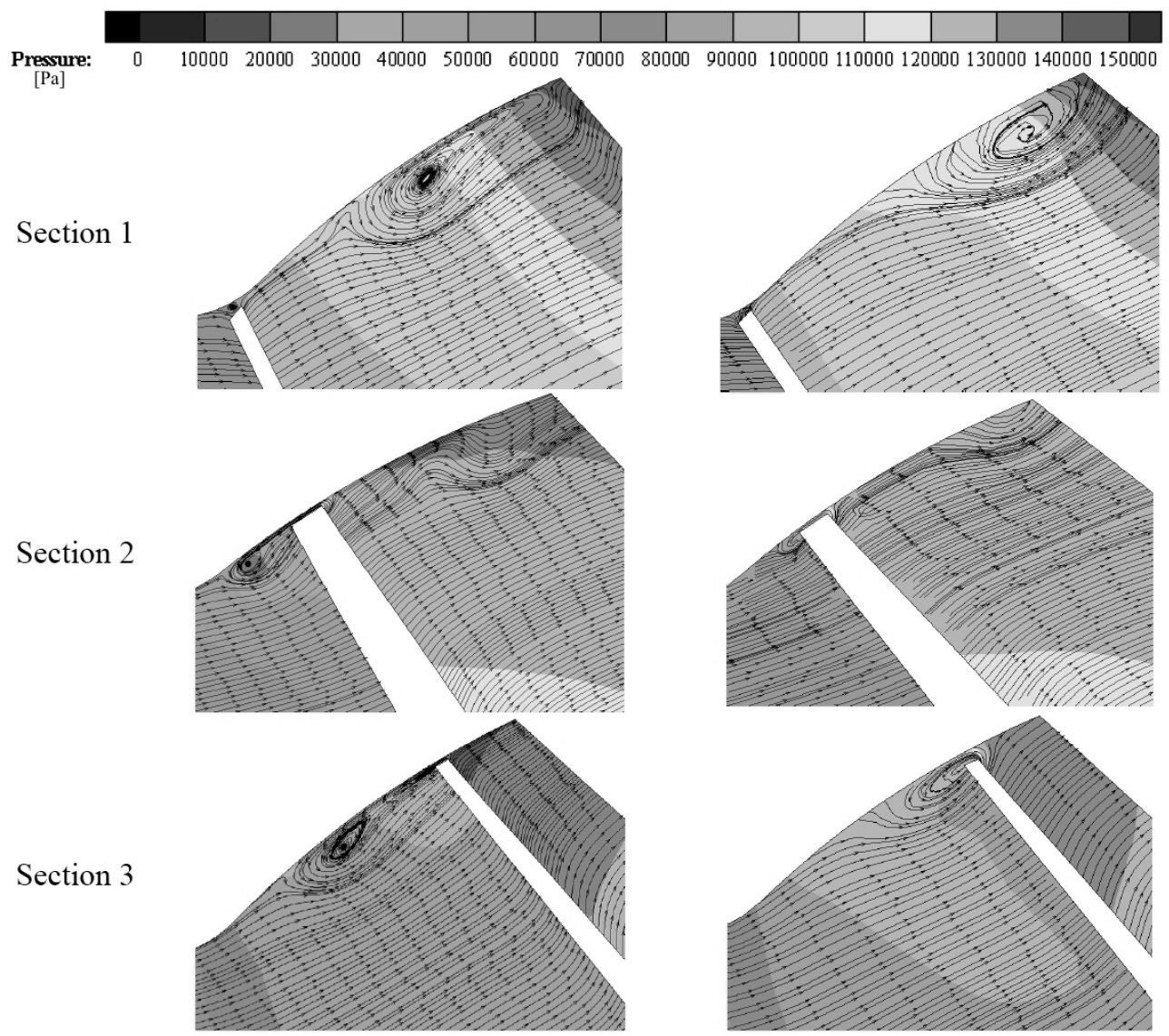

Fig. 12. Streamline diagrams and pressure nephogram of cross sections (left figures correspond to the uniform tip clearance $c=0.8-0.8 \mathrm{~mm}$ and right ones to the nonuniform one $c=0.5-1 \mathrm{~mm}$ ).

instability flow in the end-wall and forming a large number of vortices, and thus a significant energy loss is observed. This phenomenon strongly reduces the efficiency of the mixed-flow pump. With an increase in the clearance, the leakage with the nonuniform tip clearance is further increased, which is the main reason for the head drop. But the leakage flow did not form the shedding vortex, and the effect of the leakage flow on the main flow was less pronounced, as compared with that formed by the uniform clearance. 
Conclusions. The tip clearance variation has a strong influence on the performance of mixed-flow pump. The head and efficiency of the impeller with a nonuniform tip clearance is lower than that with uniform tip clearance. The head drop is more pronounced under part-load operating conditions, but the efficiency drop is more manifested under the overload operating conditions. The velocity distribution in tip area with a uniform tip clearance is more unstable than that with a nonuniform one, and the effect of leakage flow on the main one is more pronounced in the case of a uniform tip clearance.

The nonuniform tip clearance $c=0.5-1 \mathrm{~mm}$ influenced the location of the wake region by modulating the interaction between the passage and tip leakage vortices, which suppressed the leakage vortex shedding and weakened the effect of leakage vortex on the main stream. Therefore, the effect of leakage vortex may be reduced by applying a nonuniform blade tip clearance for a mixed-flow pump.

Acknowledgments. The work was supported by and the National Natural Science Foundation of China (Nos. 51409127, 51679111, and 51579118), PAPD, Six Talents Peak Project of Jiangsu Province (No. HYZB-002); Key Research and Development Projects of Jiangsu Province (Nos. BE2015119 and BE2015001-4); the Natural Science Foundation of Jiangsu Province (No. BK20161472); and Scientific Research Start Foundation Project of Jiangsu University (No. 13JDG105).

1. M. Ou, W. Shi, W. Jia, and Q. Fu, "Numerical simulation and experimental validation on hydrodynamic radial force of mixed-flow pump impeller," Trans. CSAE, 31, No. 9, 71-76 (2015).

2. R. F. Huang, X. W. Luo, B. Ji, et al., "Multi-objective optimization of a mixed-flow pump impeller using modified NSGA-II algorithm," Sci. China Technol. Sc., 58, No. 12, 2122-2130 (2015).

3. S. Shukla, A. K. Roy, and K. Kumar, "Material selection for blades of mixed-flow pump impeller using ANSYS," Mater Today - Proc., 2, Nos. 4-5, 2022-2029 (2015).

4. Y. Senoo and M. Ishida, "Deterioration of compressor performance due to tip clearance of centrifugal impellers," J. Turbomach., 109, No. 1, 55-61 (1987).

5. S. S. Hong, M. Schleer, and R. S. Abhari, "Effect of tip clearance on the flow and performance of a centrifugal compressor," Am. Soc. Mech. Eng., 1, 563-569 (2003).

6. C. Wei $\beta$, D. R. Grates, H. Thermann, and R. Niehuis, "Numerical investigation of the influence of the tip clearance on wake formation inside a radial impeller," Am. Soc. Mech. Eng., 6B, 681-691 (2003).

7. D. Wu, P. Yan, X. Chen, et al., "Effect of trailing-edge modification of a mixed-flow pump," J. Fluids Eng., 137, No. 10, 101205 (2015).

8. H. Bing, L. Tan, S. L. Cao, and L. Lu, "Prediction method of impeller performance and analysis of loss mechanism for mixed-flow pump," Sci China Technol. Sc., 55, No. 7, 1988-1998 (2012).

9. K. Wang, H. Liu, X. Zhou, and W. Wang, "Experimental research on pressure fluctuation and vibration in a mixed-flow pump," J. Mech. Sci. Technol., 30, No. 1, 179-184 (2016).

10. J. L. Lu, P. C. Guo, J. J. Feng, and X. Q. Luo, "Experimental study on the flow of a mixed-flow pump impeller," IOP Conf. Ser: Earth Environ. Sci., 15, No. 6, 062051 (2012).

11. R. Huang, B. Ji, X. Luo, et al., "Numerical investigation of cavitation-vortex interaction in a mixed-flow waterjet pump," J. Mech. Sci. Technol., 29, No. 9, 3707-3716 (2015) 
12. M. Sedláŕ, J. Šoukal, T. Krátký, and M. Vyroubal, "Numerical prediction of impacts of cavitation in pumps for power generation," Therm. Eng., 62, No. 6, 408-413 (2015).

13. M. Sedlar, O. Sputa, and M. Komarek, "CFD analysis of cavitation phenomena in mixed-flow pump,” Int. J. Fluid Mach. Syst., 5, No. 1, 18-29 (2012).

14. D. Bonaiuti, M. Zangeneh, R. Aartojarvi, and J. Eriksson, "Parametric design of a waterjet pump by means of inverse design, CFD calculations and experimental analyses," J. Fluids Eng., 132, No. 3, 031104 (2010).

15. D. J. Kim, Y. U. Min, J. Y. Kim, and K. N. Chung, "A study of tip clearance effect for a mixed-flow pump on performance," Am. Soc. Mech. Eng. (2003), DOI: 10.1115/ FEDSM2013-16346.

16. B. van Esch and L. Cheng, "Unstable operation of a mixed-flow pump and the influence of tip clearance," Am. Soc. Mech. Eng. (2011), DOI: 10.1115/AJK201106016.

17. A. Goto, "The effect of tip leakage flow on part-load performance of a mixed-flow pump impeller," J. Turbomach., 114, No. 2, 383-391 (1992), DOI:10.1115/ 1.2929155 .

18. H. Bing, S. L. Cao, C. L. He, and L. Liu, "Experimental study of the effect of blade tip clearance and blade angle error on the performance of mixed-flow pump," Sci. China Technol. Sc., 56, No. 2, 293-298 (2013). 